one section would be felt by all other sections of industrial scientists, and also by academic and Government employees. He considers that scientists as salaried workers require some type of trade union organization which would include organization of assistants. The details of such an organization would require special study, but the immediate consideration is the building up of organizations such as the Association of Scientific Workers and the British Association of Chemists.

The Liverpool Conference was held on March 4, and was opened by Mr. J. P. Lawrie with a general discussion of the questions involved. This was followed by a factual paper on assistants, their status and problems. A survey of contemporary professional organizations was then given. It was pointed out that a very large number of professional workers, such as teachers, medical men and journalists, are already organized in trade unions. In purely scientific fields the degree of organization is comparatively very low. The learned societies are precluded by their charters from activities affecting the economic conditions of their members, and the field is still open for vast development. The British Association of Chemists, with 2,000 members, has been registered as a trade union since 1920. The Association of Scientific Workers, with 1,500 members, is not now a trade union, but interests itself in economic activities. Mr. Lawrie then gave a survey of advertisements for scientific posts and a statistical analysis of the materiak collected regarding salaries was given. The position of women scientists was considered and the discrepancy in wages pointed out. It is realized that this question has increased in importance since the War began.
The Manchester Conference was held on March 16, with Prof. Willis Jackson in the chair. Prof. H. Levy, in opening the discussion, said that scientists are not brought up in an industrial atmosphere, and the idea of trade unionism is, consequently, foreign to them. He showed that the same forces operate with industrial scientists as with manual workers. $\mathrm{He}$ then analysed the different types of scientific work and discussed the impact of the War on science and on scientists. This was followed by a paper on basic salaries, increments, cost of living adjustments, etc. The question of contracts was the subject of the next paper, and the anomalies and lack of standardization was pointed out. After this, the problems of students were discussed, especially under the conditions of the War. The effect of conscription and the increase in the cost of living due to the evacuation of universities were dealt with.

The final papers dealt with the rights of publication and the problems of the laboratory assistant. In the latter, the main problems were considered to be: diversity of labour, lack of standardization, salaries, absence of status, promotion and unskilled labour, especially since the outbreak of war.

All three conferences were very well attended and were accompanied by lively discussion from the floor. The two salient features of the conferences were the realization of the growing role which the laboratory assistant takes in industrial science, and the feeling that the War is raising acute economic problems for scientists and an active organization is needed capable of protecting their interests.

A full report of the conferences will be given in the April-May number of the Scientific Worker, the organ of the Association of Scientific Workers.

\title{
DRUG STANDARDS FOR INDIA
}

$\mathrm{T}$ HE ambition of those enlightened practitioners of medicine in India who, under the leadership of Dr. Chopra, have sought for many years past to bring that country into line with the rest of the civilized world in the matter of standardized drugs now seems to be near achievement. A comprehensive measure providing for the uniform control of the manufacture and sale of drugs as well as the importation of drugs is now before the Legislative Assembly ; the introduction of such a Bill is, in itself, no small advance towards the desired goal, since the Bill is backed by resolutions from every one of the provincial legislatures empowering the central authority to pass an Act to regulate the nanufacture, distribution and sale of drugs throughout India. No such resolutions were necessary for the purpose of a measure to regulate the importation of drugs, but such limited control would fail to bring about the desired purpose, namely, to create a clean business in medical supplies in every province. It would be of little use to prohibit the importation of inferior drugs if there were no means of preventing the sophistication of imports or the domestic production of inferior preparations. The Bill, when it becomes law, will extend to the whole of India.

So far as imports are concerned, the Bill makes it an offence to import misbranded drugs, by which term is meant, briefly, drugs different from what they are represented to be by the labels on their containers. It specifically prohibits the importation of "any drug which is not of standard quality", and it is interesting to find that the standards with which compliance will be necessary are as follows: (1) proprietary medicines: the list of ingredients described on the label or the formula disclosed to the Central Drug Laboratory, as the case may be; (2) vaccines, sera, toxins and other biological products of a like nature : the standards maintained at the National Institute for Medical Research, London; (3) vitamins, hormones and analogous products : the standards maintained at the National Institute; (4) other drugs : the standards of identity, purity and strength specified in the latest edition either of the British Pharmacopoia or the British Pharmaceutical Codex or any other prescribed pharmacopœia, or adopted by the Permanent Commission on Biological Standardisation of the League of Nations. On the principle of what is "sauce for the goose is sauce for the gander", the part of the Bill which relates to domestic manufacture and to the sale and distribution of drugs is in effect the same as that which applies to the importation of drugs ; the standards to be complied with are identical in each case. 